\title{
Formulasi Perancangan Strategi Pengembangan Usaha Menggunakan Analisis SWOT dan Business Model Canvas
}

\author{
Fanji Wijaya ${ }^{1}$. Mokh. Adib Sultan ${ }^{2}$ \\ Magister Manajemen, Sekolah Pascasarjana, Universitas Pendidikan Indonesia, Bandung, Indonesia
}

\begin{abstract}
This research was conducted to study how to design a Canvas Business Model strategy that is suitable for Blackjack Distro in the face of business competition. The purpose of this study was to study the Canvas Business Model of Blackjack Distro, to connect the Blackjack Distro by analyzing Strengths, Weaknesses, Opportunities, and Threats and to study business strategies that would develop the Blackjack Distro business in Indonesia. The research method used is descriptive qualitative method. In collecting data, researchers use the interview method. Interviews were conducted with informants who were selected by purposive sampling technique. The results of this study indicate that the Blackjack Distro already has all the elements of Business Model Canvas that are the reference for business operations, but there are still things that need to be improved or expanded from. on the business of the canvas model. Blackjack Distro needs to add some business aspects in developing its business going forward such as adding product sales quantity, more innovation in product design, determining business partners, developing HR quality, increasing offline sales by participating in events, bazzar, expenditure arrangements, and additional market segmentation.
\end{abstract}

Keywords. business model canvas; distro blackjack; swot analysis.

Abstrak. Penelitian ini dilakukan untuk mengetahui bagaimana rancangan strategi Business Model Canvas yang tepat untuk Distro Blackjack dalam menghadapi persaingan usaha. Tujuan dari penelitian ini adalah untuk mengetahui Business Model Canvas dari Distro Blackjack, untuk mengevaluasi Distro Blackjack dengan menganalisis Strengths, Weakness, Opportunities, dan Threats serta untuk mengetahui strategi usaha yang tepat dalam mengembangkan usaha Distro Blackjack di Indonesia. Metode penelitian yang digunakan adalah metode kualitatif deskriptif. Dalam mengumpulkan data, peneliti menggunakan metode wawancara. Wawancara dilakukan kepada narasumber yang sudah dipilih dengan teknik purposive sampling. Hasil penelitian ini menunjukan bahwa Distro Blackjack sudah memiliki semua elemen Business Model Canvas yang menjadi acuan berjalannya usaha, tetapi masih ada yang perlu diperbaiki atau dikembangkan lagi dari Sembilan elemen yang dimiliki Distro Blackjack terdapat Strengths, Weakness, Opportunities, dan Threats dari setiap elemen yang ada pada business model canvas tersebut. Distro Blackjack perlu menambah beberapa aspek bisnis dalam mengembangkan usahanya kedepan seperti, menambah kuantiti penjualan produk, lebih inovasi lagi dalam design produk, menentukan mitra usaha, pengembangan kualitas SDM, memperbanyak jualan offline dengan mengikuti event, bazzar, pengaturan pengeluaran, dan penambahan segmentasi pasar.

Kata Kunci. business model canvas; distro blackjack; analisis swot.

Correspondence. fanjiwijaya@upi.edu

History of article. Received: April 2019, Revision: Juli 2019, Published: September 2019

\section{PENDAHULUAN}

Usaha Mikro Kecil dan Menengah (UMKM) merupakan salah satu bentuk kegiatan kewirausahaan yang berperan penting dalam pembangunan ekonomi. UMKM mampu meningkatkan standar hidup masyarakat dan berkontribusi dalam pengentasan kemiskinan (Alom, Abdullah, Moten, \& Azam, 2016). Maka dari itu usaha mikro kecil dan menengah adalah agen-agen perubahan yang sebenarnya mampu memajukan masyarakat dan dapat membawa inovasi dengan perubahan secara terus-menerus, serta dapat meningkatkan kreativitas. UMKM menjadi salah satu bidang usaha yang dapat bertahan dan menjadi pemulih perekonomian ditengah keterpurukan akibat krisis yang terjadi pada berbagai sektor ekonomi. Saat perekonomian di Indonesia memasuki masa sulit pada tahun 1998, krisis ekonomi yang terjadi justru memberikan motivasi kepada jutaan penduduk Indonesia untuk menggeluti UMKM (Suyaman, 2015).

Industri pengolahan merupakan kegiatan ekonomi yang mengolah bahan mentah, bahan setengah jadi atau barang jadi menjadi barang yang 
bernilai tambah (Profil Bisnis Usaha Mikro, Kecil, dan Menengah, Bank Indonesia, 2015).

Industri fashion di Indonesia saat ini berkembang dengan sangat pesat. Kondisi tersebut sejalan dengan semakin berkembangnya kesadaran masyarakat akan fashion yang sudah mengarah pada pemenuhan gaya hidup dalam berbusana, sehingga dapat dikatakan bahwa kebutuhan berbusana pada zaman sekarang tidak hanya untuk menutupi tubuh, tetapi juga sebagai sarana berkomunikasi dan menunjukkan gaya hidup dan identitas pemakaianya.

Perkembangan jaman juga telah mempengaruhi banyak hal, antara lain kebutuhan dan keinginan atau gaya hidup yang semakin meningkat dan beragam. Pada masyarakat yang tinggal di perkotaan mereka cenderung berpikiran relative maju. Mereka dihadapkan dengan beraneka macam tawaran barang dan jasa sehingga mereka akan selalu memilih barang dan jasa sesuai dengan kebutuhan dan tingkat pendapatan mereka. Perubahan jaman juga membuat suatu keadaan yang jauh berbeda dari jaman dulu. Saat ini konsumen lebih bebas memilih produk apa yang akan dikonsumsinya dan pada siapa mereka membeli produk tersebut.

Kota Bandung yang dikenal sebagai kota fashion memiliki peluang yang cukup besar untuk mengembangkan industri pakaian. Apalagi jika industri tersebut memiliki kontribusi bagi masyarakat dan daerah sekitarnya. Kota Bandung merupakan kota kreatif dengan potensi sumber daya manusia yang tersebar di semua wilayah Kota Bandung. Sejak dahulu Kota Bandung telah dikenal sebagai pusat perdagangan tekstil, mode, seni, dan budaya disebut juga "Paris Van Java".

Blackjack Industries merupakan bisnis dalam bidang distro yang menghasilkan produk T-shirt, kemeja, celana, jaket, sweater, dan aksesoris meliputi dompet, kaos kaki, sandal, organizer, topi, dan tas dengan merk Blackjack.

Penting bagi Blackjack untuk menjadikan produk yang berkualitas karena adanya kecenderungan dalam diri konsumen yang menghendaki barang-barang yang berkualitas, sehingga dengan kualitas produk yang disediakan diharapkan dapat memberikan dorongan dan pilihan bagi konsumen untuk membeli produk. Penyediaan produk yang berkualitas baik tidak hanya akan menarik minat tetapi dapat mempengaruhi keputusan konsumen untuk berbelanja. Hal ini memungkinkan mereka menjadi pelanggan yang setia dan pada akhirnya dapat mencapai sasaran dan tujuan perusahaan.

Menjalankan bisnis distro tidak lepas dari adanya pesaing, saat ini persaingan bisnis semakin kompetitif, setiap pelaku bisnis dituntut lebih kreatif dan inovatif guna memberikan apa yang sebenarnya di inginkan oleh konsumen dengan desain yang cukup banyak akan tetapi jumlah setiap modelnya terbatas.

Konsumen merupakan sasaran dari sebuah aktifitas bisnis, karena pada hakekatnya bisnis tidak akan berjalan tanpa adanya pembeli. Pasalnya banyak usaha lain yang mempunyai bisnis yang sama dengan modal yang lebih besar dan lebih finansial, secara otomatis memegang cakupan pasar yang lebih luas dan memproduksi barang yang cukup cepat. Jika strategi usaha dari Blackjack ini tidak tepat maka lambat laun ancaman ini menjadi hal yang serius untuk bertahan dalam persaingan bisnis ini.

Distro pesaing yang berada di sekitar Blackjack, Bandung: Unkl 347, Tosavica, Screamous, Cosmic, Badger, Rockmen, Dloops, Invictus, Ouval Research, Evil Army, Black id, House Of Smith.

Tingginya tingkat persaingan antar distro yang ada di daerah kota Bandung khususnya Jalan Trunojoyo dan sekitarnya yang menawarkan berbagai macam produk yang inovatif semakin mempertajam persaingan bisnis distro. Blackjack sebagai distro yang telah berdiri selama 25 tahun, Kini menghadapi tantangan yang serius dari para pesaingnya.

Blackjack sudah lama beroperasi atau berdiri bukan merupakan jaminan mendapatkan market share yang baik, hal ini terjadi karena persaingan yang semakin ketat yang ditunjukkan dengan munculnya distro - distro yang sejenis yang memberikan banyak pilihan produk, sehingga laba yang diperoleh oleh Blackjack mengalami pasang surut tiap tahunnya.

Kinerja Blackjack menunjukkan bahwa jumlah laba bersih mulai dari tahun 2013 ke tahun 2014 menunjukan penurunan sebesar Rp. 22.000.000 namun pada tahun selanjutnya mengalami peningkatan sebesar Rp. 24.500.000 tetapi tahun 2015 ke tahun 2016 laba bersih mengalami penurunan kembali sebesar Rp. 19.100.000,- serta tahun 2016 ke tahun 2017 juga mengalami penurunan sebesar Rp. 31.200.000,- kemudian pada tahun 2018 penurunan laba bersih cukup drastis sebesar Rp. 38.200.000,- dari tahun sebelumnya

Besar kecilnya laba perusahaan pada akhirnya dapat mempengaruhi keberlangsungan usaha itu sendiri. Jika suatu usaha berhasil mendapatkan laba, maka usaha tersebut telah mencapai manfaat bisnis. Pencapaian manfaat bisnis mengisyaratkan sebuah keberhasilan usaha (Lechner \& Dowling, 2003; Maxwell, 2003).

Seperti pada uraian latar belakang yang telah diungkap oleh peneliti di atas maka peneliti dipandang perlu untuk melakukan penelitian metode kualitatif yang dituangkan dalam judul berikut: "Formulasi 
Perancangan Strategi Pengembangan Usaha Menggunakan Analisis SWOT dan Business Model Canvas (Study Kasus Pada Distro Blackjack)"

Sebuah strategi yang dibuat oleh pelaku usaha/perusahaan harus dengan pertimbangan yang matang, dengan melakukan pengamatan terlebih dahulu dan selanjutnya melakukan penilaian terhadap apa saja yang nantinya dapat menjadi keunggulan bersaing. Dalam menjalankan aktifitas operasional setiap hari di perusahaan, para pemimpin dan manajer puncak selalu merasa bingung dalam memilih dan menentukan strategi yang tepat karena keadaan yang terus menerus berubah. Penerapan dan implementasi model bisnis yang tepat dalam suatu UMKM dapat memberikan beberapa manfaat utama yang pada gilirannya meningkatkan laba serta daya saing UMKM yang bersangkutan, dengan melakukan perbaikan dan perubahan terhadap model bisnis yang tepat UMKM dapat meningkatkan labanya melalui lini-lini bisnis dan ide-ide baru yang dapat menjadi pemasukan laba bagi UMKM

Widianti, 2016 Mengutarakan bahwa pemilihan strategi sebagai pendorong keberhasilan suatu organisasi mencapai tujuan menjadi penting, Pemilihan strategi tepat jika pada tahap awal dilakukan identifikasi dan pemetaan kondisi organisasi. Selain itu, sinergitas strategi terhadap tujuan atau sasaran lembaga juga penting dibangun supaya strategi yang dipilih dapat mendukung pencapaian tujuan organisasi.

\section{KERANGKA PENELITIAN}

\subsection{Konsep Entrepreneur}

Konsep entrepreneur ialah "An entrepreneur is one who creates a new business in the face of risk and uncertainty for the purpose of achieving profit and growth by identifying significant opportunities and assembling the necessary resources to capitalize on them. Although many people come up with great business ideas, most never act on their ideas.".(M. Scarborough \& R. Cornwall, 2016).

Entrepreneur adalah orang yang menciptakan bisnis baru dalam menghadapi risiko ketidakpastian untuk tujuan mencapai laba dan pertumbuhan dengan mengidentifikasi peluang dan memanfaatkan sumber daya yang ada. Proses persaingan kreatifitas, di mana pengusaha menciptakan ide-ide baru dan bisnis baru yang membuat ide yang sudah ada menjadi usang. Meskipun bisnis terus-menerus berubah ada yang naik, tenggelam, yang baru berhasil, dan banyak yang gagal, pada kenyataannya adalah indikasi sehat, sistem ekonomi yang berkembang menciptakan caracara baru dan lebih baik untuk melayani kebutuhan dan meningkatkan kualitas hidup dan standar hidup mereka.

\subsection{Manajemen Strategi Bisnis}

Untuk mencapai tujuan organisasi atau bisnis diperlukan alat yang berperan sebagai akselerator dan dinamisator sehingga tujuan dapat tercapai secara efektif dan efisien. Sejalan dengan hal tersebut, strategi diyakini sebagai alat untuk mencapai tujuan perusahaan. Strategi adalah rencana yang disatukan menyeluruh dan terpadu yang dirancang untuk memastikan bahwa tujuan utama organisasi dapat dicapai melalui pelaksanaan yang tepat oleh organisasi (Fred R \& David, 2017).

\subsection{Business Model Canvas (BMC)}

Business Model Canvas (BMC) salah satu alat strategi yang digunakan untuk mendeskripsikan sebuah model bisnis dan menggambarkan dasar pemikiran tentang bagaimana organisasi menciptakan, memberikan, dan menangkap nilai. Mengubah konsep bisnis yang rumit menjadi sederhana yang ditampilkan pada satu lembar kanvas berisi rencana bisnis dengan sembilan elemen kunci yang terintegrasi dengan baik didalamnya mencangkup analisis strategi secara internal maupun ekternal perusahaan (Osterwalder \& Pigneur, 2017).

Berikut adalah Sembilan elemen Business Model Canvas:

1. Segmen pelanggan (Customer Segments)

Customer Segments adalah pihak yang menggunakan jasa atau produk dari organisasi dan mereka yang berkontribusi dalam memberikan penghasilan bagi organisasi. Pelanggan adalah pihak yang membayar jasa atau produk untuk barang belanjaannya. Pembayaran pihak konsumen untuk aliran dana masuk dan akan diberikan kepada organisasi.

2. Proporsi nilai (Value Proposition)

Value Proposition merupakan satu keunikan yang menetukan mengapa produk atau jasa tersebut pantas dipilih oleh pelanggan. Ini memberikan tawaran untuk memecahkan masalah pelanggan atau semaksimum mungkin memenuhi keinginan pelanggan. Keunikan yang ditawarkan harus memberikan tonjolan yang berbeda dibandingkan bisnis pesaing dan didambakan oleh konsumen.

3. Saluran menuju pelanggan (Channels) Channel atau elemen yang menyatakan bagaimana organisasi berkomunikasi dengan pelanggan segmennya dan menyampaikan value proposition-nya. Komunikasi, distribusi, dan saluran penjualan adalah faktor-faktor yang memungkinkan perusahaan berinteraksi dengan 
pelanggan. Channel meliputi cara-cara meningkatkan kesadaran (awareness) memudahkan pelanggan menilai, membantu pelanggan membeli produk atau jasanya, menyampaikan produk atau jasanya, dan memberi bantuan purna jual.

4. Hubungan dengan pelanggan (Customer Relationship)

Pembinaan hubungan dengan pelanggan bertujuan untuk mendapatkan pelanggan baru (akuisisi), mempertahankan pelanggan lama (retention), dan menawarkan produk atau jasa lama dan baru pada pelanggan lama.

5. Aliran pendapatan (Revenue Streams)

Revenue Streams atau aliran dana masuk menggambarkan bagaimana organisasi memperoleh uang dari setiap customer segments. Aliran dana inilah yang memungkinkan organisasi tetap hidup. Pada intinya ada dua jenis pendapatan yaitu bersifat transaksional dan yang berbentuk pengulangan (recurring). Beberapa contoh pendapatan transaksional adalah penjualan produk atau jasa, sedangkan yang bersifat pengulangan terdiri dari penyewaan asset, langganan, dan keanggotaan.

Banyak organisasi yang berusaha memperbanyak recurring income karena tidak membutuhkan usaha pemasaran yang yang berat, dan memberikan kepastian aliran dana.

6. Sumber daya kunci (Key Resources)

Key Resources menggambarkan asset-aset terpenting yang menentukan keberhasilan pengoperasian model bisnis. Aset-aset berharga inilah yang memungkinkan organisasi mewujudkan value proposition yang dijanjikannya kepada pelanggan dengan baik. Sumber daya kunci dapat berupa sumber daya fisik (bangunan, kendaraan, peralatan), uang, asset intelektual (merek, hak cipta, paten, data base pelanggan), dan sumber daya manusia. Dari keempat sumber daya ini, sumber daya intelektual merupakan salah satu asset yang sangat penting karena sulit ditiru.

7. Kegiatan-kegiatan kunci (Key Activities)

Kegiatan inti adalah kegiatan yang menentukan keberhasilan suatu model bisnis. Key activities berperan penting dalam mewujudkan value proposition. Tidak semua kegiatan perlu dicantumkan, akan tetapi kegiatan lain cukup dilakukan dengan memenuhi strandar minimal.

8. Mitra Kunci (Key Partnership)

Kemitraan kunci merupakan mitra kerja sama pengoperasian organisasi. Organisasi membutuhkan kemitraan ini untuk berbagai motif yang umumnya adalah penghematan karena tidak tercapainya ekonomi skala, mengurangi resiko, memperoleh sumber daya atau pembelajaran

9. Biaya-biaya (Cost Structure)

Struktur biaya menggambarkan semua biaya yang muncul sebagai akibat dioperasikannya model bisnis ini. Semua upaya mewujudkan value proposition, melalui channel yang tepat, key resources, dan key activities yang handal, semuanya membutuhkan biaya. Struktur biaya dipengaruhi oleh strategi perushaan yang dipilih, apakah mengutamakan biaya rendah atau mengutamakn manfaat istimewa. Selain itu struktur biaya juga dipengaruhi oleh besarnya biaya tetap, biaya variabel, ekonomi skala (economy of scale) dan ekonomi cakupan (economy of scope)

\subsection{Analisis SWOT}

Menurut Boseman dalam Wisnubroto \& Freitas, 2013, analisis SWOT (SWOT analysis) adalah proses penarikan kekuatan, kelemahan, kesempatan dan ancaman dalam organisasi dan dunia bisnis dikenal sebagai penaksiran atau analisis SWOT.

\section{METODE PENELITIAN}

Penelitian ini merupakan penelitian deskriptif dengan menggunakan pendekatan kualitatif, menurut (Sugiyono, 2013) penelitian kualitatif adalah penelitian yang berlandaskan pada filsafat postpositivisme, digunakan untuk meneliti pada kondisi objek yang alamiah, (sebagai lawannya adalah eksperimen) dimana peneliti adalah sebagai instrumen kunci, pengambilan sampel sumber data dilakukan secara purposive dan snowball, teknik pengumpulan dengan menggunakan trianggulasi (gabungan), analisis data bersifat induktif / kualitatif, dan hasil penelitian lebih menekankan makna dari pada generalisasi.

Hasil penelitian ini nantinya hanya mendeskripsikan atau mengkonstruksikan wawancara secara mendalam terhadap subjek penelitian yang sedang kita teliti agar nantinya dapat memberikan gambaran yang jelas mengenai penerapan business model canvas di dalam pengembangan Strategi Business Model Canvas Dalam Menghadapi Persaingan (Study kasus pada Distro Blackjack).

Data yang dikumpulkan dari penelitian ini berasal dari dua sumber yaitu:

Data primer yaitu data yang diperoleh langsung dari lapangan baik melalui observasi, dokumentasi maupun melalui wawancara dengan pihak informan. 
Metode pengambilan data primer menggunakan cara wawancara langsung terhadap pemilik, karyawan maupun konsumen pada Distro Blackjack.

Data sekunder, yaitu berupa dokumen-dokumen atau literatur-literatur dari Badan Pusat Statistik (BPS), internet, jurnal, skripsi. Pengumpulan data sekunder dilakukan dengan mengambil atau menggunakan sebagian/seluruhnya dari sekumpulan data yang telah dicatat atau dilaporkan

Dalam (Sugiyono, 2013) mengemukakan bahwa aktivitas dalam analisis data kualitatif dilakukan secara interaktif dan berlangsung secara terus menerus sampai tuntas, sehingga datanya sudah jenuh. Artinya dalam analisis data perlu adanya penggalian informasi secara terus menerus agar informasi yang didapatkan benar-benar lebih mendalam dan sudah sampai titik pusat terhadap informasi yang kita inginkan

\section{HASIL DAN PEMBAHASAN}

Berikut hasil dan pembahasan dari wawancara yang dilakukan oleh peneliti dapat dipetakan dalam business model canvas sebagai berikut:

\subsection{Business Model Canvas Distro Blackjack}

\begin{tabular}{|c|c|c|c|c|}
\hline Key partners & 3 Key activities & Value propositic & Costumer relationships & Costumer segments \\
\hline $\begin{array}{l}\text { 8. Investor } \\
\text { - Vendor } \\
\text { - Photographer } \\
\text { - Owner-owner } \\
\text { brand lain } \\
\text { - Shipping partner: } \\
\text { jne } \\
\text { - Endorser and paid } \\
\text { promote Instagram } \\
\text { artis } \\
\text { - Terang mulya \& } \\
\text { kenari }\end{array}$ & $\begin{array}{l}\text { 7. Melayani } \\
\text { konsumen setiap } \\
\text { waktu, Quality } \\
\text { control, Pengiriman } \\
\text { setiap hari }\end{array}$ & $\begin{array}{l}2 \text { Harga yang } \\
\text { ekonomis di } \\
\text { banding dengan } \\
\text { kompetitor lain, } \\
\text { Menyediakan } \\
\text { Produk kaos dengan } \\
12 \text { ukuran khusus, } \\
\text { Menggunakan } \\
\text { bahan baku terbaik, } \\
\text { Desain produk baru } \\
\text { setiap bulan }\end{array}$ & $\begin{array}{l}\text { 4. Pelayanan yang } \\
\text { ramah, Selalu } \\
\text { memberikan informasi } \\
\text { mengenai produk } \\
\text { Blackjack }\end{array}$ & $\begin{array}{l}\text { 1. Anak muda, } \\
\text { pelajar, mahasiswa, } \\
\text { mahasiswi }\end{array}$ \\
\hline \multicolumn{5}{|l|}{ Cost structure } \\
\hline \multicolumn{2}{|c|}{$\begin{array}{l}\text { 9. Biaya Produksi, Biaya Marketing, } \\
\text { Biaya Operasional, Biaya Bahan Baku }\end{array}$} & \multicolumn{3}{|c|}{$\begin{array}{l}\text { 5. Penjualan produk-produk Blackjack (T-shirt, kemeja, } \\
\text { celana, jaket, sweater, dan aksesoris meliputi dompet, } \\
\text { kaos kaki, sandal, organizer, topi, dan tas dengan } \\
\text { merk Blackjack) }\end{array}$} \\
\hline
\end{tabular}

Sumber: Distro Blackjack, 2019

Gambar 1. Business Model Canvas Distro Blackjack 4.2 Analisis SWOT Business Model Canvas Distro Blackjack

Setelah mendapatkan gambaran Business Model Canvas Distro Blackjack, langkah selanjutnya adalah melakukan analisis SWOT pada setiap elemen Business Model Canvas Distro Blackjack. Hal tersebut dilakukan untuk mengetahui kekuatan, kelemahan, peluang, dan ancaman yang dimiliki oleh Distro Blackjack. Analisis SWOT dapat membantu menyempurnakan dan mengembangkan gambaran Business Model Canvas yang dimiliki oleh Distro Blackjack. Business Model Canvas Distro Blackjack yang baru diharapkan dapat membantu Distro Blackjack untuk menentukan strategi yang tepat dalam mengembangkan usahanya dengan meminimalisir kekurangan yang ada

\subsection{Rekomendasi Business Model Canvas Distro Blackjack}

Dari hasil analisa SWOT pada Business Model Canvas Distro Blackjack, peneliti mendapatkan hasil gambaran Business Model Canvas yang baru untuk Distro Blackjack. Berikut gambaran Business Model Canvas hasil dari evaluasi analisis SWOT:

1. Customer Segment

Setelah melakukan analisis SWOT pada Business Model Canvas Distro Blackjack, hasil evaluasi customer segment ialah perlu memperbanyak segmentasi pasar seperti memasuki pasar menengah (para star up), menengah ke bawah dengan produk yang sesuai dan memasuki segmentasi pasar anak

2. Value Position

Setelah melakukan analisis SWOT pada Business Model Canvas Distro Blackjack, hasil evaluasi value position ialah perlu memperbanyak jumlah produk penjualan sehingga selalu ready stock, selalu berinovasi dan berkreasi dalam design produk, dan menyediakan custom design untuk konsumen

3. Channel

Setelah melakukan analisis SWOT pada Business Model Canvas Distro Blackjack, hasil evaluasi channel ialah perlu memperbanyak penjualan offline dengan mengikuti banyak

event atu bazar, dan memperbanyak mitra untuk promosi produk.

4. Customer Relationship

Setelah melakukan analisis SWOT pada Business Model Canvas Distro Blackjack, hasil evaluasi customer relationship ialah perlu memperbanyak promo yang menarik untuk konsumen, menambah pengawasan terhadap mitra, dan membuat custom design untuk konsumen.

5. Revenue Streams

Setelah melakukan analisis SWOT pada Business Model Canvas Distro Blackjack, hasil evaluasi revenue streams ialah adalah perlu memperbanyak mengikuti event atau bazar sehingga bisa meningkatkan penjualan produk dan memperbanyak kolaborasi dengan brand lain.

6. Key Resources

Setelah melakukan analisis SWOT pada Business Model Canvas Distro Blackjack, hasil evaluasi key resources ialah perlu mengembangkan kualitas 
pekerja dan perlu menambah pengawasan terhadap mitra.

7. Key Activities

Setelah melakukan analisis SWOT pada Business

Model Canvas Distro Blackjack, hasil evaluasi key activities ialah perlu memperbanyak jumlah produk penjualan, memperbanyak mengikuti event atau bazar, memperbanyak variasi design produk dan perlu mengikuti pelatihan pengelolaan biaya.

8. Key Partnership

Setelah melakukan analisis SWOT pada Business Model Canvas Distro Blackjack, hasil evaluasi key partnership ialah perlu mencari mitra utama untuk distro blackjack, mencari mitra yang membutuhkan pengeluaran biaya yang minim dengan kinerja yang baik, dan memperbanyak media partner untuk pemasaran produk

9. Cost Structure

Setelah melakukan analisis SWOT pada Business Model Canvas Distro Blackjack, hasil evaluasi cost structure ialah perlu mengikuti pelatihan pengelolaan biaya yang tepat dengan modal yang terbatas dan mencari mitra yang membutuhkan pengeluaran biaya yang minim dengan kualitas yang baik.

\section{KESIMPULAN}

Dalam menjalankan usahanya, Distro Blackjack sudah memiliki atau memenuhi sembilan elemen Business Model Canvas, tetapi masih belum maksimal dalam menjalankannya. Dari Sembilan elemen Business Model Canvas tersebut Distro Blackjack masih perlu memperbaiki model bisnisnya. Dengan menganalisis Business Model Canvas dari Distro Blackjack dengan analisis SWOT, Distro Blackjack memiliki kekuatan, kelemahan, peluang, dan ancaman dalam menjalankan usahanya.

Hasil evaluasi dari analisis SWOT tersebut, menghasilkan rekomendasi gambaran Business Model Canvas yang baru untuk Distro Blackjack. Dari sembilan elemen Business Model Canvas yang dimiliki oleh Distro Blackjack, peneliti merekomendasikan bahwa Distro Blackjack perlu menambahkan aspekaspek yang ada pada Sembilan elemen tersebut.

\section{REKOMENDASI}

Berdasarkan hasil penelitian diperoleh hasil yang menunjukkan bahwa business model canvas sangat berpengaruh terhadap kemajuan bisnis di Distro Blackjack. Manajemen Distro Blackjack akan mendapatkan ilmu untuk mengembangkan bisnisnya dengan memetakannya secara terperinci sesuai dengan kesembilan elemen business model canvas. Penulis mencoba memberikan rekomendasi dalam setiap elemen business model. Distro Blackjack diharapkan akan secara efisien menyalurkan nilai untuk segmentasi konsumen yang membutuhkan kreativitas dan inovasi dalam mengoptimalisasikan hubungan dengan pelanggan, tidak terpengaruh oleh monopoli atau kebijakan yang dibuat oleh distro lain yang pada hakekatnya Distro Blackjack memiliki khas dan perbedaan masing masing.

\section{DAFTAR PUSTAKA}

Alom, F., Abdullah, M. A., Moten, A. R., \& Azam, S. M. F. (2016). Success Factors of Overall Improvement of Microenterprises in Malaysia: an Empirical Study. Journal of Global Entrepreneurship Research, 6(7), 1-13. https://doi.org/10.1186/s40497-016-0050-2

Fred R, D., \& David, F. R. (2017). Strategic Management. (S. Wall, Ed.) (SIXTEENTH). Soult Carolina. Retrieved from https://www.academia.edu/37684383/Fred_R _David_Forest_R_David_Strategic_Managemen t_A_Competitive_Advantage_Approach_Conce pts_and_Cases-backup_1_.pdf

Lechner, C., \& Dowling, M. (2003). Firm Networks: External Relationships as Sources for The Growth and Competitiveness of Entrepreneurial Firms. Entrepreneurship and Regional Development, 15(1), 1-26. https://doi.org/10.1080/08985620210159220

M. Scarborough, N. \&, \& R. Cornwall, J. (2016). Essentials of Entrepreneurship and Small Business Management (Eight Edit). U.S.A.

Maxwell, T. P. (2003). Considering Spirituality: Integral Spirituality, Deep Science, and Ecological Awarness, 38(2), 257-276.

Pigneur, A. O. dan Y. (2017). Business Model Generation. New Jersey: John Wiley \& Sons, Inc.

Sugiyono. (2013). Metode Penelitian Pendidikan, Penelitian Kuantitatif, Kualitatif dan R\&D (pp. 116). CV. Alfabeta, Bandung.

Suyaman, D. J. (2015). Kewirausahaan dan Industri Kreatif (p. 3). Bandung: Alfabeta. 
Widianti, T. (2016). AMTeQ 2015 Annual Meeting on Testing and Quality, (October 2015).

Wisnubroto, P., \& Freitas, J. M. (2013). Strategi Pemasaran Guna Meningkatkan Volume Penjualan Deangan Pendekatan Technology Atlas Project Metod. Journal Management. Yogyakarta. 